4. Al respecto, véanse los dos párrafos finales en Los cinco entierros de Pessoa. pág. 20. Véase también Tierra de nadie (con minúscula), pág. 73 de Los cinco entierros de Pessoa, que está en la pág. 34 del presente volumen. Igual con $A$ deshoras, con mínimas modificaciones de párrafos, en Los cinco entierros de Pessoa, pág. 105, y en el presente volumen, págs. 78-79.

5. Américo Ferrari, Para esto hay que desnudar a la doncella. Obra poética (I9491997), Juan Manuel Roca (introducción), Barcelona, El Bardo, I998, págs. 5-9.

6. Casa de nadies, Lima, Gonzalo Pastor editor, 2000. El poema en cuestión es el primero.

7. Enrique Sánchez Hernani, Vinilo. 42 poemas del rock'n'roll $+\mathrm{I}$ bonus track, Lima, El Fauno Editores, 2006. Clásico indiscutible. Anoten, interesados.

\section{De la dificultad para atrapar una mosca}

(ג)

\section{Oración del impuro}

Rómulo Bustos Aguirre

Universidad Nacional de Colombia,

Bogotá, 2004, 322 págs.

Ramón Cote ha intuido que la poesía colombiana del siglo XXI empieza con Oración del impuro, de Rómulo Bustos. Estoy de acuerdo. El sutil alquimista de Santa Catalina de Alejandría transmuta en un instante en oro el pesado metal de la vida. Y lo hace como Derek Walcott, desde el Caribe: entre ritmos africanos, una lentísima putrefacción de Celia, naufragios asperjados de luz, palenqueras con tesoros blancos en los dientes, camaleones a la orilla del tiempo y ángeles que quieren probar el dulce de tamarindo.

Rómulo Bustos ha enseñado pacientemente a contemplar a Dios en todas partes, a ver en todo El oscuro sello de Dios. Su asunto es sólo el arrobamiento: "En lo hondo del traspatio, más allá del mango está la poesía". El escritor no necesita salir de casa. Sus paseos imaginarios por el jardín son suficientes: "No es ne- cesario que salgas de casa - afirma Kafka en uno de sus luminosos aforismos-. Quédate junto a tu mesa y escucha. Ni siquiera escuches, espera. Pero ni siquiera esperes, quédate completamente quieto y solo. Se te ofrecerá el mundo para el desenmascaramiento, no puedes hacer otra cosa, extasiado se retorcerá ante ti".

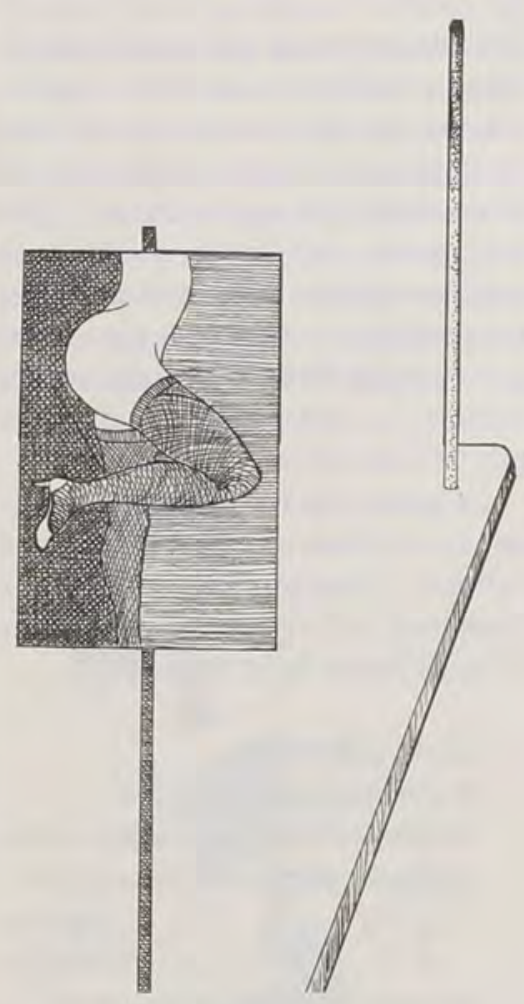

En ciertos momentos de gracia, la luz se muestra agradecida con el poeta y llega sola: "Si bajara los párpados lentamente con el recuerdo del color amarillo / caerían las frutas más altas de los árboles". El tema de Rómulo Bustos es, pues, la mística. Con el vocablo mystes se designaba al adepto a los misterios, el que arruga los ojos para mirar bien lejos. Según esta acepción, los términos mística, miopía y misterio derivarían de una misma y única raíz. Si el poeta no cerrase los ojos, someramente, acabaría por no ver lo que vale la pena de ser visto.

BORGIANA
Dulce es imaginar que la ágil
[flecha
florecerá en su inmovilidad de
[siglos

que el raudo Aquiles jamás hará Iun festin con la tortuga

La paradoja de Zenón de Elea le sirve al escritor para proponernos su poética, donde la inmovilidad (intuición del instante) es el centro de la imagen. El poeta es el arquero que dispara porque sí, sin esperar nada a cambio. Si dispara esperando algo a cambio ya tiene dos blancos. El premio lo divide. Piensa más en vencer que en disparar y la necesidad de ganar le quita el poder. Este no es el caso de Rómulo Bustos, quien lentamente $\mathrm{y}$ al margen ha ido construyendo su propio mundo. La dirección analógica hace de la imagen su eje estructural.

La metáfora es la forma mágica del principio de identidad. La música verbal es un acto catártico por el cual la metáfora, la imagen (flecha lanzada al ser) se libera de toda referencia significativa, para no aludir y no asumir sino la esencia de los objetos. Esto supone un tránsito inefable, ser sus objetos en el plano ontológico:

\section{La rosa súbita que florece en el pecho del ciervo herido acaso redima el alma del}

razador

El dominio de la analogía y la alegoría queda dividido así en territorio poético y territorio 'lógico'. Este tejido comprende todo un juego de "correspondencias" entre espíritu y materia, razón e intuición. El poeta canta a un objeto, sabiendo que se apropia de su esencia, en un acto nominalista, animista y metafísico:

\section{EL PERPLEJO}

"Lleva el alma de regreso a [casa" aconseja el sabio tibetano

$Y$ si el alma extravía los pasos len el camino

$Y$ si no hay camino

$Y$ si no hay casa

Y si no hay alma que llevar de

Iregreso a casa

Nace la poesía de Rómulo Bustos de una ruptura en un orden, de un he- 
chizo. La palabra se revela como prenda o talismán. Analogía, porque su poesía no parece venir de nadie, de nadie visible. Ascetismo es renuncia. El alma se ha devorado a sí misma, transformándose en otra cosa. Esta mística es en Rómulo Bustos quietud y aplacamiento. Autofagia: mónada sin ventanas, el alma humana del místico sólo ha de hallar remedio en devorar su propia cárcel, su propia alma.

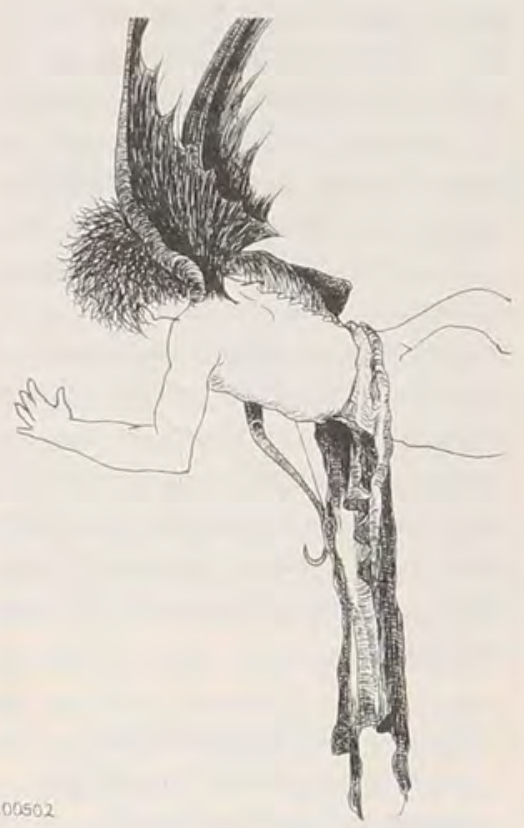

UN PACO-PACO

[...]

Miro el animalito tratar en vano [de frotar la una con la no-otra pata

$y$ me es inevitable evocar el

[conocido epigrama zen que enigmáticamente se

Ipregunta: ¿Cómo es el sonido Ide una sola mano cuándo aplaude?

Existe, acaso, ese sonido?

$Y$ tú, Bustos, tratas también de

Ifrotar, de desplegar Itus dos patas traseras,

tu ala única

$[\ldots]$

Escribir es lo interminable e incesante para el poeta. En ausencia de tiempo el soñador sabe que su esencia es la soledad. Y la esencia del lenguaje poético, el silencio: la música callada. En Rómulo Bustos la palabra no es sólo comunicación sino también conocimiento (conocimiento haciéndose). La actividad poética en Oración del impuro es revelación de lo encubierto:

\section{TINAJA \\ En la forma de la arcilla se abrazan \\ las preguntas del agua}

Todo hace pensar que las aporías de Zenón de Elea acerca de la imposibilidad del movimiento, y con ello de la historia también, depende de la situación del poeta mismo. Que si la flecha está donde no está y, si está, no avanza. Que si Aquiles no puede alcanzar a la tortuga será porque el poeta no está presente ante sí mismo, no está despierto, dándole plenamente la cara a la realidad.

El poeta vuelve al tiempo original como linde de dos mundos: la infancia (nacimiento) y la vejez (muerte), allí encuentra la revelación (el fuego de su llama).

\section{EL PAJARERO \\ A este hombre lo vi niño \\ llevando en sus manos una jaula \\ Un poco más usado el gesto de}

rociosa

inocencia

lo sigue llevando como quien Iporta una luz

o un distraído sueño

El pájaro ya no está

En verdad nunca ha estado

Pero, a veces, se detiene y aguza fal aire el oído

como si escuchara su canto

En un juego de paradojas, contradicciones y antítesis se mueve la escritura de Rómulo Bustos. No desacralizando el mundo, sino volviéndolo a llenar de magia (misticismo vacuo). El autor percibe la historia como una inquietante y excitante discontinuidad. Quiere, a través del mito, fundar su propia legitimidad.

La Oración del impuro se ocupa de lo fronterizo, lo oscuro, lo indeciso, lo incierto y, en general, de todo aquello que descarta el saber positivo y científico. El poeta es el que se refugia en un dominio ambiguo don- de la fantasía y la libertad imperan, a la par que experimenta un sentimiento de nostalgia de un paraíso perdido.

Entre la beatitud y el abismo se mueve la poesía de Rómulo Bustos Combinando doctrinas teosóficas, herméticas y esotéricas. Restaura el eclecticismo hedónico, la ironía y el sincretismo estilístico. Mito y poesía se confunden, en el límite de lo verbalmente comunicable:

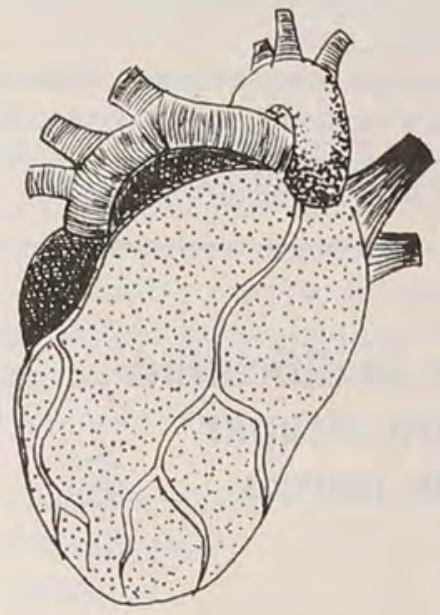

COTIDIANO

Como sucede con los cuadros Ique cuelgan en las paredes cada mañana sorprendes una leve inclinación de tu

ladentro

Cada mañana crees corregir este [desnivel

Pero entre la primera posición y queda siempre un residuo lla segunda una brizna de polvo que se

[acumula

Sobre esta oscura aritmética se ledifica tu alma

Esta nueva sensibilidad de Rómulo Bustos reclama el verso libre, la elipsis y los silencios como sus principales armas. El poeta crea una poesía metafísica en el Caribe. Es capaz de visualizar lo irreal en el tedio y el sopor de Macondo. Su escritura polivalente recupera la inquietud, la fluidez y el dinamismo de un mundo entre "enormes huevos prehistóricos" congelados en el tiempo. 
Poesía para el siglo xxI que devuelve a la palabra los íntimos poderes. Palabra desprejuiciada, sin inhibiciones ni vedas, que devuelve la libertad plenaria a la metáfora para "ir más allá" de lo real verificable, antídoto contra una existencia alienada. Melquíades, el alquimista, vislumbra la utopía, la completud que el orden imperante imposibilita.

JORGE H, CADAVID

\section{"Poesía de postrimerías"}

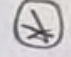

\section{Candiles en la niebla}

Héctor Rojas Herazo

Ediciones Uninorte, Barranquilla,

2006, 8I págs.

Editado por la Universidad del Norte, en asocio con la Secretaría de Cultura y Patrimonio de la Gobernación del Atlántico, con prólogo del poeta Juan Manuel Roca, precedido de una reflexión del autor acerca de los trabajos del poeta y los prodigios de la poesía, ilustrado, además, con sus propios dibujos, sale a luz Candiles en la niebla, el libro de poemas que Héctor Rojas Herazo tenía listo para publicar cuando el I I de abril de 2002 lo acogió, como diría Álvaro Mutis, la muerte con todos sus sueños intactos.

Encabezando el poemario, aunque sin la mención de su título, figura como epígrafe un poema del propio Rojas, perteneciente a su libro inmediatamente anterior, Las úlceras de Adán, Epitafio, que consta de sólo dos versos: "Tanto viví mi muerte, que ahora sueño / morir de vida en azorados huesos". El epígrafe, en apariencia funeral, que nos remite a los poemas metafísicos de Quevedo, que no hallaban cosa en qué poner los ojos que no trajera el recuerdo de la muerte y su reino de espanto con sus presentes sucesiones de difuntos y el horror de la hora que huye en fuga irrevocable, da el tono y la temperatura del libro en el que, como en el barroco, los contrarios se unen, se alían, borran sus fronteras y la vida y la muerte, la luz y la sombra, el cielo y el infierno, las llagas de Dios y las del hombre, ángeles y demonios, el incienso y el azufre, el culpable y el cómplice, el verdugo y la víctima, revelan su similitud, "su luz de sombra", su "sol de caverna", su íntima unidad. El poema Instante es un testimonio de ese encuentro entre entidades opuestas: "Ya sabemos que la rosa / es aroma de la espina / y que el consuelo lo forja / el dolor que nos destruye. Pero sabemos también / que un triste fulgor nos sueña / caminando sin destino / por donde ni existe polvo / para trazar un camino" (pág. 9).

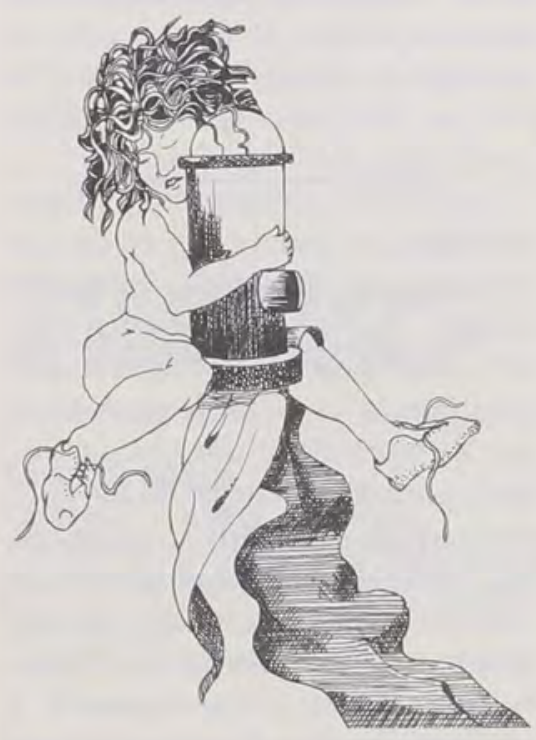

Lo primero que llama la atención de este libro es la calidad de la edición desde el formato, el color y la textura hasta el papel, pasando por las ilustraciones y la diagramación que permiten leer de manera casi simultánea los poemas y los dibujos, percibir su intercambio de señales. La segunda sorpresa es el prólogo de Juan Manuel Roca, su precisa caracterización del poemario, su destino de talismán acompañante, "hecho, más que de palabras, de jirones de luz, de secretos revelados por el poder de la lengua $[\ldots]$ más allá de esteticismos y de ningunerías, más allá de alardes verbales y ritmos predecibles $[\ldots]$ donde no hay artilugios, artes de taumaturgo en un tinglado". Cabe destacar, así mismo, la certera selección de los versos de Rojas que Roca cita: son sin discusión los que piden la pista de aterrizaje de la memoria para quedarse allí para siempre.

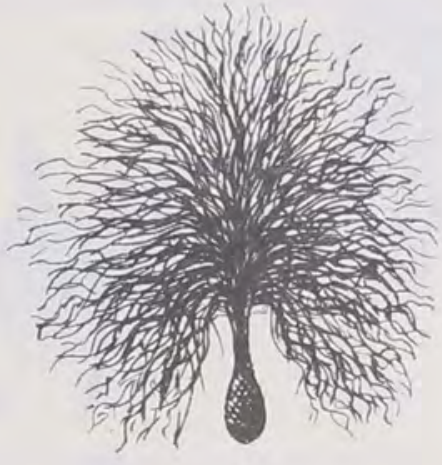

La tercera sorpresa sucesiva es el texto "Anhelando alcanzar la explicación del prodigio", ponencia de Rojas Herazo en el Segundo Congreso de Poesía en lengua española desde la perspectiva del siglo XXI que se efectuó en Bogotá del I 2 al 17 de agosto de 2001 , en la que el poeta Rojas expone las directrices de su poética preocupada por avivar los sentidos del hombre, apresar y descifrar, en un instante, el enigma de todo lo viviente, y comunicar, a través del poder de metamorfosis de la palabra, que torna en ternura y convierte en consuelo, ensueño y recuerdo, el sufrimiento y el pesar, la inclemencia y la destrucción, "la terrible experiencia de vivir alimentado por la muerte". Para ilustrar sus intuiciones Rojas se apoya en ejemplos de poetas que van de Omar Kayan a Nicolás Guillén, pasando por el cante jondo, Garcilaso, Quevedo, Miguel Hernández, Guillermo Valencia y Juan Lozano y Lozano, revelándonos la apertura de su conocimiento poético así como la amplitud de su gusto personal, inmune a modas.

Con los faros o las teas de los prólogos puede el lector ingresar sin riesgo de traspiés en las nieblas del poe ma. Y no tiene nada de raro que sea a raíz de esta experiencia previa que la entrada en los poemas nos produz- 